\title{
FINANCIAL INSTRUMENTS' MEASUREMENT IN ROMANIA: FROM CHALLENGE TO LESSON LEARNING
}

\author{
Carmen Giorgiana Bonaci $^{1}$, Jiří Strouhal ${ }^{2}$, Razvan V. Mustata $^{3}$ \\ ${ }^{1}$ Babes-Bolyai University Cluj-Napoca, Romania, carmen.bonaci@econ.ubbcluj.ro \\ ${ }^{2}$ University of Economics Prague, Czech Republic, strouhal@vse.cz. \\ ${ }^{3}$ Babes-Bolyai University Cluj-Napoca, Romania,r.v.mustata@gmail.com \\ cross ${ }^{\text {ref }} \mathrm{http} / / / \mathrm{dx}$.doi.org/10.5755/j01.em.17.1.2245
}

\begin{abstract}
The objective of the paper is to provide an analysis on Romanian valuers' perceptions of fair value determination and to show whether there exist a direct connection between the dimension of the developed activity and the valuers' level of professional training. The developed analysis uses information being obtained through implementing a questionnaire addressed to Romanian valuers. The questionnaire followed information regarding main aspects in valuers' professional activity: their professional training, their professional activity in the field of accounting for financial instruments, fair value measurement and also on some fundamental aspects related to the recent financial crisis. Second part of the analysis being develop in this study was dedicated to documenting an association between valuers' professional activity and their professional training. Results document the sustainability of the proposed regression model and documents that when considering the national market of valuation services in the field of financial instruments, there is a direct connection between the dimension of the developed activity and the valuers' level of professional training.
\end{abstract}

Keywords: Financial instruments' measurement, accounting professionals, fair value, financial crisis, transformation.

JEL Classification: M41.

\section{Introduction}

Paper focuses on accounting professionals being involved in financial instruments' measurement process. The transition from communism to capitalism imposed professionals to witness a series of transformation processes. It is the perception of these processes and their impact upon the profession that we are trying to capture.

Besides the transformation processes taking place at national level we must also acknowledge the dynamic being imposed by events taking place in the international arena. All these considerations were helpful in designing our research demarche through which we have tried to capture such complex processes. Therefore, besides the above mentioned research design aspects, we have also chosen to focus on a more narrow aspect in the activity of professionals in the area of accounting, concretely on activities related to financial instruments' measurement process.

There must be mentioned the shift in accounting paradigms leading the accounting model from historical cost measurement towards fair value measurements. The international trend of using fair value as measurement base for most of the financial instruments and for a series of other key elements capturing entities' financial position, was significantly impacted by the recent financial crisis. Both financial instruments, especially derivatives, and their fair value measurement were placed in the center of all analysis being developed in relation to the recent events. Even if a significant number of studies (see Veron, 2008; André et al., 2009) defend the concept of fair value in the context of the financial crisis, documenting how fair value ended up by being either the scapegoat or the shot messenger, it was the turbulent times of 20072009 that brought a series of shortcomings of the concept even more into the spotlight (Bonaci and Strouhal, 2011). Shortcomings and difficulties of mark to market accounting were significantly enhanced, bringing a series of doubts regarding further moves toward more widespread use of fair value measurements.

Moreover, recent market conditions of the credit crunch and reduced market liquidity brought significant challenges for users, preparers and auditors of financial statements, especially in terms of measurement issues. Under such circumstances, we considered it interesting to capture the perception of national accounting professionals being involved in the measurement process of financial instruments. Considering the fact that Romanian capital market cannot be compared with developed capital markets where most of the problematic issues usually arise, we were expecting our respondents to have a low level of experience in the area of financial instruments measurement, or to put it from valuers' point of view, financial assets' valuation. On the other hand, lifelong learning requires professionals to always be connected to the developments taking place even at higher levels than those involved by their daily activity, therefore 
preparing themselves to be competitive on the international market. This makes it even more interesting for us to follow the manner in which the profession, which only two decades ago was dealing with switching from one political system to another, copes with the above described dynamics.

\section{Theoretical Background}

Before developing the proposed analysis we consider it necessary to briefly present an overview of historical evolutions taking place in Romanian accounting system. Immediately after the fall of the communist regime, Romania started an ample process of moving from a centralized economy towards market-based economy. The process then being started and the reforms that followed proved to be difficult and complex, affecting multiple areas of the economic activity, including accounting (Filip and Raffournier, 2010 , p. 84). The change taking place in the political regime in 1989 also caused serious necessities of chance in the area of regulation in order to better manage the new state of facts within the Romanian economy and society. Introducing new accounting regulations and changing the accounting system became an obvious reality. In fact, we could state that the political choice which was made in 1991 relied on three major aspects: (i) the need for implementing a new accounting system (after "getting out of the Russian school"); (ii) the necessity of adopting accounting measures which were compatible with the prescriptions within the EU Accounting Directives, since the country was a candidate for EU accession; and also (iii) the need of identifying an inspirational resource, since there was no time for creating a new internal accounting system, the euphoria of becoming a EU member requiring quick reforms in different fields (Matis et al., 2012).

There must be also mentioned significant changes taking place at the level of the national accounting regulation process. Established in 2005, the Council of Accounting and Financial Reporting in Romania (CCRF) is appointed responsible for the development of the institutional framework in the field of accounting and of the accounting profession in 2007. CCRF plays the role of a consultative and analysis body in the process of elaborating Romanian accounting regulations and does not have a juridical personality and functions beside the Romanian Ministry of Finance. The project for a strategy in the field of accounting regulation related to private entities is now within the CCRF agenda. The note grounding this strategy mentions two significant aspects. The first is explicitly mentioning the intention of applying IFRS for all companies listed on the Romanian capital market, besides consolidated financial statements that obey the EU endorsement of IFRS. The second is requiring the development of a documentation process referring to the manner in which other member states acted and to the difficulties being encountered in relation to IFRS adoption.

Since paper focuses on accounting professionals, there must be mentioned the study being developed by Matis et al. (2012) documenting the segmentation of a profession that comprises two representative professional bodies at national level - The Body of Expert and Licensed Accountants of Romania (CECCAR) and The Chamber of Financial Auditors of Romania (CAFR). Considering the objective of this paper we have chosen to focus this analysis on expert valuers who are members of the Body of Expert and Licensed Accountants of Romania, as well as on members of the National Association of Romanian Valuers (ANEVAR). The members of the later professional body on the Romanian labour market to be closely linked to this study's focus on measurement aspects. There has to be also stated that many professionals in Romania are actually members within all of the four professional bodies being previously introduced. This documents the segmentation of the national accounting profession, assuming a number of professional bodies fighting for supremacy on the market for similar services.

\section{Research Methodology}

The developed analysis uses information being obtained through implementing a questionnaire addressed to Romanian valuers. The questionnaire represents the main research instrument being used and was directly administered to our sample valuers through an electronic communication channel.

With reference to the structure of the questionnaire, it comprised two distinctive parts and an introduction which had the purpose of making the objective of this study known to the respondent. The two distinctive parts were following: (i) first part was oriented towards obtaining general information regarding the respondent's professional activity; (ii) second part comprised a series of questions that made reference to the particularities of financial instruments' measurement.

The first part followed information regarding three main aspects in valuers' professional activity, as follows: their clients, their professional training, and their professional activity in the field of accounting for 
financial instruments. Second part was dedicated to technical and professional aspects in the area of financial instruments, focusing on particularities of the national regulations, on the issue of fair value measurement and also on some fundamental aspects related to the recent financial crisis.

The number of professional valuers, regardless of their belonging to one professional body or the other, to whom the questionnaire was sent, is of 1960 , while the response rate was only $6.07 \%$.

\section{Descriptive Analysis and Its Results}

The first aimed aspect refers to the respondents' clients. Only around 5\% of the respondents mainly develop their activity in the area of financial instruments.

Analysis also focused on valuers' professional activity by considering the respondents' professional training. A first aspect being considered in this regard was their knowledge in the field of financial instruments. We found that $38 \%$ of the respondents considered they had a medium level of knowledge in the field of financial instruments, while only one person considered he was extremely well prepared in the approached field. Beyond looking at the valuers' acknowledgement of their knowledge in the field of financial instruments, we considered it appropriate to also look at their ability to transfer knowledge towards third parties and particularly towards other professionals in the area of valuation. In this regard we also formulated a question that allowed us to check the accuracy of the previously received answers, analyzing whether the respondents had been teaching any professional training courses in the field of financial instruments. As expected, in accordance to their previous responses, only 7 professionals had been experiencing the position of lecturers for financial assets' valuation.

In order to obtain further details regarding the manner in which valuers develop their activity in the area of financial instruments' measurement respondents were asked which methods they used in practice when dealing with financial assets' measurement. The most often mentioned methods were comparisons with trading of similar instruments being issued by comparable companies or with previous transactions of the same instruments and the discounted cash-flow method. The obtained responses document that professionals frequently rely on information that is taken from the market, respondents often mentioning comparisons with other transactions on the market whenever these are possible. Under such circumstances we consider that correctly assessing the information being obtained from the market, as well as adequately integrating this information in the measurement process becomes vital.

When asking valuers "How do you assess the usefulness of fair value as measurement base for financial instruments?" respondents seem to asses it has at least a medium usefulness. The responses document that 51 respondents agree with the switch in accounting paradigms taking place in the international arena. We also found some of the valuers considering that capturing the dynamic of financial instruments goes beyond the capabilities of accounting practices:

Financial instruments have, every moment, the precise value being posted on the market. Any computation is linked only to the intention of investing / keeping / selling. Their variation is so dynamic that accounting cannot capture it in an exact manner.

Respondent 3

The next step was to record valuers' perception regarding fair value's definition. Only little over half of the respondents considered that fair value should be defined as an exit value from the perspective of the financial asset's or financial liability's owner. Since previous answers were documenting valuers' approval of the IASB's regulations, it was to a certain extant expected for them not to embrace the definition being issued by the Financial Accounting Standards Board (FASB). Arguments were offered both for and against the use of exit values in defining fair value:

In the case of redundant assets and those with an active market; still, also for other assets, an indication regarding the exit value can be necessary, at least for comparison/reporting.

Respondent 4

No. Because the exit-price represents a market value (generally lacking control and in certain cases including the lack of liquidity), while fair value (both in an accounting meaning and a legal one - of fairness) can be different from the market value.

Respondent 23

Several other aspects were investigated in relation to fair value, such as the possibility of its determination when considering financial instruments that assume inactive market conditions. Little over $90 \%$ of the respondents consider that only a medium possibility exists to measure financial instruments at fair value within such a market. Comments being presented by the respondents show a certain degree of 
discontent in relation to the trust being offered by users to the results of measurements that assume significant use of professional judgment. Valuers seemed to be especially discontent with such measurements being challenged despite their professional ability to adapt to the particularities of the mission that involved the valuation. We consider the respondents assuming their professional activity despite the difficult circumstances of the market being affected by the recent financial crisis to document a responsible and constructive attitude.

Ultimately, I guess it is possible, even though difficult, to present a reasonable judgment even under such circumstances. The problem is that, due to causes such as: an inactive market or the lack of access to reliable information on private transactions, the result of our work to be easy to challenge, not necessarily from well grounded reasons. Under such circumstances, this aspect makes the valuer's work significantly harder, offering greater significance to expressions such as "the value is subjective", "the value is only valid at the measurement date", "the value is valid under the mentioned limitative conditions and hypothesis" etc. We should not forget that using estimated values is often done much later after the measurement date. For example, if a bank executes a mortgage at a two years period after the loan was accepted. The value which could be too small is increased. But in case that period was characterized by a significant real estate decline, what would the problem be? It is similar for the capital market.

Respondent 15

Another aspect being brought to respondents' attention was the use of management's assumptions in order to measure financial instruments based on internal generated models. This of course for those circumstances that do not allow fair value measurement based on level 1 and level 2 inputs. The obtained answers document strong disagreements in relation to this manner of determining fair value for financial instruments when considering inactive capital markets. Some opinions are even placed at opposed poles, from total trust in such measurement methods based on internal models to emphasizing its shortcomings:

It represents the only reliable source of information.

Respondent 19

Management's assumptions cannot be independent and objective.

Respondent 7

Meanwhile a series of opinions seem to weight the usefulness of such information being provided by the management and to find their utility, but with caution and by always looking for alternative ways to confirm the obtained values:

Management's internal assumptions must only be considered to the extent that they can also be validated through data and information taken from the issuer's industry and respectively from the market, generally.

Respondent 12

A practice that is recommended in the area is to develop a critical analysis of these assumptions, together with the entity's management, in order to see if they are "in the market" or rather "outside the market".

Considering the fact that most of the times management has more information on the market than the valuer, you are actually playing on thin ice.

Respondent 15

All available information must be used.

Respondent 21

The responses also certify the central role played by financial instruments being even more brought to the spotlight through crisis circumstances. Some considered crisis also brought opportunities for well trained valuers in the area of financial assets to prove their ability and to contribute to finding some feasible solutions:

The crisis led to the increase of the percentage for these services and the decline of services in the real estate area.

Respondent 15

The current financial crisis will affect the practice of financial instruments' measurement only to a small extant due to the fact that the importance of these existent assets will increase, many of them now not being known or appreciated by users/their owners, and the costs of the important ones will increase. We already see foreign investors (the Poland stock exchange) making big investments on the Bucharest Stock Exchange.

Respondent 51

Another aspect being emphasized through the responses makes reference to the difficulties being imposed to valuers, in their professional activities, by the recent capital market circumstances:

The market's volatility makes it that market information and data are no longer relevant and reliable. It is therefore difficult to make forecasts under uncertainty circumstances that characterize the crisis.

Respondent 12 
The used data are vulnerable to the influence of impairments that are difficult to handle and argue for.

Opinions that disagreed with the fair value concept were extremely rare, as well as those considering that valuers already benefit of sufficient resources of information on fair value:

The concept already appears within the International Valuation Standards and is being used by valuers. I do not consider it necessary to popularize the concept beyond the sphere of those working with it. The National Association of Romanian Valuers regularly organizes training seminars that also cover this concept.

Respondent 21

\section{Determinants of Valuers' Professional Activity}

The second part of the analysis being develop in this study was dedicated to documenting an association between valuers' professional activity and their professional training. The tendency to develop behaviors that subscribe to the idea of lifelong learning is nowadays acting worldwide. While in 1990 we only had a single professional body in the area of accounting in Romania, we are currently witnessing the dispute for supremacy between no less than four professional bodies (Matis et al., 2011).

Under such circumstances we consider it necessary to dimension the association between the dimension of the developed professional activity and the training level a professional held at one moment in time. We propose the following set of research hypotheses:

$\boldsymbol{H}_{0}$ : $\quad$ When considering the market for valuation services in the area of financial assets (financial instruments' measurement) there is no direct connection between the dimension of the developed activity and the valuers' level of professional training.

$\boldsymbol{H}_{1}$ : $\quad$ When considering the market for valuation services in the area of financial assets (financial instruments' measurement) there is a direct connection between the dimension of the developed activity and the valuers' level of professional training.

As it can also be seen from the above formulated hypotheses, we are once again dealing with two dimensions and their association makes the object of our analysis.

The first dimension is that of the professional activity being developed by valuers. Due to study's focus on financial instruments we have chosen to quantify this dimension by considering the percentage of clients asking for services in the field of financial instruments. We consider this element to be opportune due to the fact that the quality of the services being provided is usually quantified through turnover and clients portfolio.

The second dimension being mentioned above refers to the valuers' level of professional training. This dimension will further be quantified by considering a series of elements which we considered could represent determinants of valuers' professional activity. Among these factors we must mention valuers' level of knowledge, number of training programs being followed, actual training period, as well as the level of details being provided when grounding the results of a valuation mission. The following table synthesizes the elements (variables) being considered for analysis in a structured manner:

Table 1. Synthetic data on the considered variables

\begin{tabular}{|c|c|}
\hline Variables & Coding used \\
\hline \multicolumn{2}{|l|}{ Dependent variables } \\
\hline $\begin{array}{l}\text { The percentage of clients asking for services related } \\
\text { to financial instruments. }\end{array}$ & $\begin{array}{l}1 \text { - very low; } 2 \text { - low; } 3 \text { - medium; } 4 \text { - high; } 5 \text { - very high; } \\
0 \text { - there are no such clients. }\end{array}$ \\
\hline \multicolumn{2}{|l|}{ Independent variables } \\
\hline $\begin{array}{l}\text { Level of knowledge in the field of financial } \\
\text { instruments. }\end{array}$ & $\begin{array}{l}1 \text { - very low; } 2 \text { - low; } \\
3 \text { - medium; } 4 \text { - high; } 5 \text { - very high. }\end{array}$ \\
\hline $\begin{array}{l}\text { Training programs followed in the field of financial } \\
\text { instruments. }\end{array}$ & $\begin{array}{l}\text { Number of training programs: } 1 \text { - very low; } 2 \text { - low; } 3 \text { - } \\
\text { medium; } 4 \text { - high; } 5 \text { - very high. }\end{array}$ \\
\hline $\begin{array}{l}\text { How recent is the latest followed training program in } \\
\text { the field of financial instruments? }\end{array}$ & $\begin{array}{l}\text { The level is considered to be: } \\
1 \text { - very low; } 2 \text { - low; } 3 \text { - medium; } 4 \text { - high; } \\
5 \text { - very high; } 0 \text { - he/she did not follow such programs. }\end{array}$ \\
\hline $\begin{array}{l}\text { Teaching within training programs in the field of } \\
\text { financial instruments. }\end{array}$ & $1-$ Yes; $0-$ No. \\
\hline $\begin{array}{l}\text { How detailed is the presentation made when } \\
\text { grounding the developed valuations? }\end{array}$ & $\begin{array}{l}\text { Level of particularization: } 1 \text { - very low; } 2 \text { - low; } 3 \text { - } \\
\text { medium; } 4 \text { - high; } 5 \text { - very high. }\end{array}$ \\
\hline
\end{tabular}


All values corresponding to the above presented variables were taken out of the database being constructed based on the answers which were obtained by questionnaire implementation. The used research instrument was therefore applied to the information being offered by the 62 valuers who responded to our questionnaire in a complete manner which we were able to validate.

In order to document the analyzed association we developed regression analysis. Considering the typology of the variables being used and the fact that the dependent variable is a qualitative one, being dimensioned on a five points Likert scale ( 1 representing the lower level and 5 the higher level), we developed an ordinal regression analysis.

On the other hand, we considered that all valuers participating in the study belonged to a single group of analysis for which we first employed descriptive analysis, followed by implementing an ordinal regression model. More precisely we used the Negative $\log$-log function due to the structure of the data being analyzed and mainly to the distribution of values of the dependent variable. Therefore, the proposed ordinal regression model is the following:

$$
\begin{gathered}
\text { Activity }=\alpha+\beta_{1} \text { AKnowledge }+\beta_{2} \text { NTrainings }+\beta_{3} \text { ATrainings }+\beta_{4} \text { LecturerPoz }+\beta_{5} \text { ValueBase } \\
+\varepsilon_{i}
\end{gathered}
$$

where:

Activity

represents the dimension of the activity being developed by the valuers, expressed by considering the percentage of clients asking for services in the area of financial instruments;

AKnowledge represents the valuers' declared level of knowledge in the field of financial instruments;

NTrainings $\quad$ represents the number of training programs in the field of financial instruments followed by the valuers;

ATranings $\quad$ expresses how recent is the latest training program in the field of financial instruments being followed by the valuers;

LecturerPoz considers whether valuers also use to teach training programs in the field of financial instruments;

ValueBase represents the level of particularization and details being offered when grounding a developed valuation.

As previously mentioned, descriptive analysis was employed before developing the regression model. The obtained results are presented within Table 2:

Table 2. Descriptive statistics for the considered variables

\begin{tabular}{|l|r|r|r|r|r|r|}
\hline & Activity & AKnowledge & NTrainings & ATrainings & LecturerPoz & ValueBase \\
\hline Mean & 0.95 & 2.73 & 1.79 & 2.61 & 0.11 & 3.23 \\
\hline Median & 0.50 & 3.00 & 2.00 & 3.00 & 0.00 & 3.00 \\
\hline Minimum & 0 & 1 & 0 & 0 & 0 & 1 \\
\hline Maximum & 5 & 5 & 5 & 5 & 1 & 5 \\
\hline Std dev. & 1.408 & 1.104 & 1.473 & 1.832 & 0.319 & 1.062 \\
\hline Skewness & 1.801 & -0.259 & 0.407 & -0.277 & 2.507 & -0.471 \\
\hline Kurtosis & 2.361 & -0.979 & -0.721 & -1.373 & 4.429 & -0.300 \\
\hline Observations & 372 & 372 & 372 & 372 & 372 & 372 \\
\hline
\end{tabular}

The following step assumed the implementation of the proposed regression model. Two complementary tests were applied in order to document the sustainability of the developed regression model, namely the Likelihood ratio test and the Chi-square goodness of fit. The values being recorded when running the Cox-Snell $\mathrm{R}^{2}$ and Nagelkerke measure tests were also analyzed for the same purpose. Results are presented within Table 3: 
Table 3. Results of ordinal regression analysis

\begin{tabular}{|c|c|c|c|}
\hline & $\begin{array}{c}\text { Coefficient } \\
\text { Estimate }\end{array}$ & Wald $\chi^{2}$ & P-value \\
\hline \multicolumn{4}{|c|}{ Independent Variables } \\
\hline AKnowledge (+) & 19.880 & 295.737 & 0.000 \\
\hline NTrainings (+) & 0.124 & 0.135 & 0.043 \\
\hline ATrainings (+) & -1.366 & 2.461 & 0.021 \\
\hline LecturerPoz (+) & 0.082 & 2.585 & 0.042 \\
\hline ValueBase (+) & -1.709 & 2.994 & 0.028 \\
\hline
\end{tabular}

Model $\chi^{2}=46.757, \mathrm{p}<0.000$.

Pearson Chi-Square $=168.632, \mathrm{p}$-value $=0.999$

Deviance Chi-Square $=88.867, \mathrm{p}$-value $=1.000$

\section{Pseudo R-Square}

Cox-Snell

Nagelkerke

\section{Test of Parallel Lines}

Chi-Square $=99.781, \mathrm{p}$-value $=0.035$

All independent variables being considered were previously defined.

\section{Discussion}

The results document the sustainability of the proposed regression model. Furthermore, the values being obtained when running the Cox-Snell $\mathrm{R}^{2}$ and Nagelkerke measure tests allow us to consider that valuers' professional activity in the field of financial instruments is determined in an approximately $50 \%$ proportion by their professional training.

If we are to make reference to the particular research hypothesis which we formulated at the beginning of this part of analysis in this study, considering the fact that for the whole model the Chi-Square test generated a value of 46.757 , while $p$-value $=0.000$, there could be stated the null hypothesis is rejected and the alternative hypothesis is accepted. The results document the fact that when considering the national market of valuation services in the field of financial instruments, there is a direct connection between the dimension of the developed activity and the valuers' level of professional training under the above mentioned circumstances.

We consider results to represent incentives for valuers to invest in their professional training. On one hand this will significantly contribute to increasing their competitiveness on the labor market and also their ability to keep pace with developments taking place in the international arena. The better trained professionals who easily perform under current economic circumstances we have, the better are the chances that their contribution makes a difference in the dynamics of the international arena even if by starting at a national level. On the other hand, as documented by the second part of our analysis, the better trained they are, the higher are the chances for them to expand their professional activities.

\section{Acknowledgment}

This work was supported by project number POSDRU/89/1.5/S/59184 'Performance and excellence in postdoctoral research within the field of economic sciences in Romania', and by project P403/11/0002 registered at Czech Science Foundation (GA ČR).

\section{References}

1. André, P., Cazavan-Jeny, A., Dick, W., Richard, C., \&Walton, O. (2009). Fair Value Accounting and the Banking Crisis in 2008: Shooting the Messenger. Accounting in Europe, 6(1-2), 3-24.

2. Bonaci, C. G., \& Strouhal, J. (2011). Fair Value Accounting and the Regulation of Corporate Governance. Economics and Management, 16, 14-20.

3. Filip, A., \& Raffournier, B. (2010). The Value Relevance of Earnings in a Transition Economy: The Case of Romania. The International Journal of Accounting, 45(1), 77-103.

4. Matis, D., James, K., Mustata, R. V., \& Bonaci, C. G. (2012). Romanian Accounting Profession: Erudition and Perspectives. International Journal of Critical Accounting, forthcoming.

5. Veron, N. (2008). Fair Value Accounting Is the Wrong Scapegoat for This Crisis. Accounting in Europe, 5(2), 63-69. 